\title{
The impact of procalcitonin to C-reactive protein ratio (PCR) kinetics as a predictor of mortality in nosocomial bloodstream infections
}

Ismail Necati Hakyemez ( $\sim$ drhakyemez@gmail.com )

Balikesir University https://orcid.org/0000-0001-6133-9604

Turan Aslan

Bezmialem Vakif University

Bulent Durdu

Bezmialem Vakif University

Research article

Keywords: Procalcitonin, C-reactive protein, Bloodstream infection, Mortality

Posted Date: September 8th, 2020

DOI: https://doi.org/10.21203/rs.3.rs-55584/v2

License: (c) (i) This work is licensed under a Creative Commons Attribution 4.0 International License.

Read Full License 


\section{Abstract}

Purpose: To investigate the combination of serum C-reactive protein (CRP) and procalcitonin (PCT) kinetics in predicting mortality in nosocomial blood stream infections (BSIs).

Materials and Methods: We retrospectively reviewed the medical records of patients $\geq 18$ years of age with nosocomial BSIs hospitalized in intensive care units (ICU). Clinical, microbiological and biochemical data were compared in patients who survivors and deaths. Binary logistic regression analyses were used to identify independent risk factors. The kinetic changes were defined the as difference between level on 5 th day and level at 1 st day of BSI.

Results: Of the 84 included patients, $49(58.4 \%)$ had survivors and $35(41.6 \%)$ had deaths. In univariate analysis, renal disease $(p=0.007)$, cardiac disease $(p=0.042)$, septic shock $(p=<0.001)$, SOFA $(p=<0.001)$ and APACHE-II $(p<0.001), \triangle C R P(p=0.004), \triangle P C T(p=<0.001)$, and $\triangle P C R(p=0.025)$ were significantly higher in non-survivors. In the logistic regression analysis, APACHE-II score $(\mathrm{OR}=1.46,95 \% \mathrm{Cl}=1.20-1.78, \mathrm{p}$ $<0.001), \triangle \mathrm{CRP}(\mathrm{OR}=1.18, \% 95 \mathrm{Cl}=1.04-1.34, \mathrm{p}=0.009), \triangle \mathrm{PCT}(\mathrm{OR}=0.87,95 \% \mathrm{Cl}=0.79-0.95, \mathrm{p}=0.001)$, and $\triangle \mathrm{PCR}(\mathrm{OR}=36.78,95 \% \mathrm{C}=4.52-299.01, \mathrm{p}=0.001)$ were independent predictors of 28-day mortality.

Conclusions: The $\triangle \mathrm{PCR}$ kinetic was a strong independent predictor of mortality in nosocomial BSIs in ICUs.

\section{Introduction}

The structure of nosocomial infections is dynamic and complex and often involves a large number of variables that adversely affect clinical outcomes [1]. Bloodstream infections (BSIs) in hospitalized patients are the leading cause of morbidity and mortality, and their early diagnosis and appropriate treatment is critical for positive outcome [2-4].

The inflammatory response is the main determinant of the unfavorable long-term consequences of sepsis. Biomarkers that can be used as an independent prognostic factor in assessing mortality should be objectively measured to reflect inflammatory processes and therapeutic responses [5]. These, together with their positive clinical results, also contribute significantly to health care costs. However, improper test requests and interpretations can also lead to unnecessary administration and procedures to patients [6]. Biomarkers need to provide a fast, common, and reliable method of identification. Existing biomarkers cannot fully reflect these features [7]. They do not replace a comprehensive clinical evaluation, but they increase the support data, the clinician must make rational decisions [6].

The level of C-reactive protein (CRP) increases significantly in response to infection. However, it is also increasing in all non-specific, inflammatory disorders. CRP provides only limited information on infection status and is far from a perfect test for diagnosing critical diseases [7-9]. CRP can be detected in the blood within 4 to $6 \mathrm{~h}$ after bacterial challenge and peaks at 36 to $50 \mathrm{~h}$ [9]. Procalcitonin (PCT) is an indicator of systemic inflammation and can help predict bacteremia, sepsis and mortality [10-14]. PCT 
concentrations rise rapidly, 2 to $3 \mathrm{~h}$ after bacterial infections, and PCT has a shorter half-life than that of CRP [9]. It differs better between CRP between infectious and non-infectious causes of critical disease [7]. PCT is useful as a parameter for predicting early systemic bacterial infections. PCT measurements in series can help predict mortality in sepsis and reduce antibiotic exposure [6, 9]. Albumin (ALB) tends to decrease in levels during acute infections and is a strong indicator of outcome in infectious diseases. The relationship between low serum albumin level and high mortality has been reported in several studies [15, 16].

Recently, the effectiveness of various biomarkers such as CRP, PCT, albumin, which can be used in clinical practice is investigated on sepsis and mortality. It has been stated that PCT to ALB ratio (PAR) is an early diagnostic factor in predicting sepsis, patients with high rates are more prone to septic shock [17]. CRP to ALB ratio (CAR) has been reported to correlate with hospital mortality, sepsis, and poor prognosis in patients with cancer $[5,18,19]$. There were two reports on the usefulness of PCT to CRP ratio (PCR) in various infectious conditions of adult patients $[20,21]$. It has been shown that the PCR can help differentiate proven sepsis from suspected sepsis when used with PCT in late onset neonatal sepsis [22].

In patients diagnosed with nosocomial BSI, a simple, fast and accessible parameter is needed to predict treatment response and mortality. In this study, we aimed to determine a more valuable predictor by comparing various inflammatory variables in predicting treatment response and mortality in BSIs.

\section{Materials And Methods}

\section{Patients and Study Design}

This retrospective study was conducted in Bezmialem Vakif University Hospital which has 28-bed adult intensive care units (ICU), totally 550 beds. Adult patients aged $\geq 18$ years in ICU diagnosed with BSIs during the period from January 2016 to June 2018 were included in the study. Patients with recurrent BSIs with the same microorganism and insufficient laboratory data were excluded.

\section{Data Collection}

Daily BSI surveillance have been done at our hospital by visiting patients and checking their laboratory results by the infection control team. Basic characteristics, medical history, comorbidities, sepsis/septic shock, microorganisms defined in hemoculture, laboratory parameters (including PCT and CRP), and antimicrobial treatment on $1^{\text {st }}$ day of BSI have been recorded to surveillance forms. Maximum SOFA (sequential organ failure assessment) and APACHE-II (Acute Physiology and Chronic Health Evaluation-II) scores on $1^{\text {st }}$ day of BSI were calculated according to patients' digital records. In patients with suspected BSI, CRP and PCT levels are routinely checked daily or every 2 days. PCR was calculated based on routine laboratory parameters involving CRP (normal range values $0-0.5 \mathrm{mg} / \mathrm{dL}$ ) and PCT (normal range values 0-0.05 ng/ml).

\section{Definition}


BSIs was diagnosed and recorded during daily active surveillance according to Centers for Disease Control and Prevention criteria [23]. Sepsis and septic shock diagnosis were made according to recent guidelines [24]. Primer outcome was determined as 28-day mortality rates. We evaluated the predictive ability of CRP, PCT, and their combination PCR. PCT, CRP, and PCR kinetic changes were expressed as $\triangle \mathrm{PCT}, \triangle \mathrm{CRP}$, and $\triangle \mathrm{PCR}$. For example, $\triangle \mathrm{PCT}$ defined the difference between PCT level on $5^{\text {th }}$ day and PCT level at $1^{\text {st }}$ day of BSI. Values $<0$ indicated decreasing PCT concentrations. CRP or PCR kinetics were also expressed in the same way. [25].

\section{Statistical analysis}

Categorical variables were presented as absolute frequency and percentage, and continuous variables were presented as mean, standard deviation (SD), Standard Error of Mean (SEM). The clinical characteristics of the two groups, survival and death, were compared using the Pearson's chi-squared test or Fisher's exact test for categorical variables, and the Student's-t independent test for continuous variables. Paired Student's t-test was used to compare the measurements at two time points (between the 5th day and 1st day) for CRP, PCT, and PCR. For the logistic regression analysis, univariate analysis was performed first, and $p$ values of less than 0.05 were considered statistically significant. Additionally, binary logistic regression ("backwards: LR" method) was used. Analysis of the receiver operating characteristic (ROC) curves and the area under the curves (AUCs) were performed to evaluate the $\triangle P C R$ as predictive values for mortality in critically ill patients. In addition, we compared the ROC curves between the $\triangle \mathrm{CRP}, \triangle \mathrm{PCT}$ and $\triangle \mathrm{PCR}$. All statistical analyses were performed with IBM SPSS software version 22.0 (IBM, Armonk, NY, USA).

\section{Ethics}

The study protocol was approved by the Ethics Committee of the Hospital of Bezmialem Vakif University. The informed consent form was not needed because of the retrospective nature of the study.

\section{Results}

Of the 84 included patients, $49(58.4 \%)$ had survivors and $35(41.6 \%)$ had deaths. The mean age was $63.6 \pm 17.5$ years. The most common underlying disease was neurological disease $(n=41,48.8 \%)$, followed by hypertension ( $n=37,44.1 \%)$; and diabetes mellitus was found in $30(35.7 \%)$ of these patients. The maximum SOFA and APACHE II scores were $8.5 \pm 2.9,18.5 \pm 5.2$, respectively. The 28-day mortality was $41.6 \%(n=35)$; remaining patients were defined as survivors. The comparison of demographic, clinical, laboratory, treatment parameters between deaths and survivors is shown in Table 1. In univariate analysis, diseases severity scores, maximum SOFA $(p=<0.001)$ and APACHE-II $(p<0.001)$ were significantly higher in non-survivors. Non-survivors had a higher prevalence of underlying renal disease $(p=0.007)$, cardiac disease $(p=0.042)$, and septic shock $(p=<0.001)$. In laboratory findings, platelet count $(p=0.004)$ was lower in non-survivors than in survivors. In addition, $\Delta C R P(p=0.004)$, 
$\triangle P C T(p=<0.001)$, and $\triangle P C R(p=0.025)$ were significantly higher in non-survivors than in survivors (Table 1).

In the logistic regression analysis (backward stepwise LR), adjusted for comorbidities, and empiric treatment. APACHE-II score (odds ratio $(\mathrm{OR})=1.46,95 \%$ confidence interval $(\mathrm{Cl})=1.20-1.78, \mathrm{p}<0.001$ ), $\triangle \mathrm{CRP}(\mathrm{OR}=1.18, \% 95 \mathrm{Cl}=1.04-1.34, \mathrm{p}=0.009), \triangle \mathrm{PCT}(\mathrm{OR}=0.87,95 \% \mathrm{Cl}=0.79-0.95, \mathrm{p}=0.001)$, and $\triangle \mathrm{PCR}(\mathrm{OR}=36.78,95 \% \mathrm{Cl}=4.52-299.01, \mathrm{p}=0.001)$ were independent predictors of 28-day mortality (Table 1).

The blood culture positive group was classified into gram-positive bacteria, gram-negative bacteria, and fungal infections in patients with nosocomial BSI (Table 2).

Figure 1 shows the ROC curves of $\triangle \mathrm{CRP}, \triangle \mathrm{PCT}$, and $\triangle \mathrm{PCR}$. The AUC for $\triangle \mathrm{PCR}$ was $0.745(95 \%$ confidence interval (Cl) $0.62-0.87, \mathrm{p}<0.001$ ); this was greater than the AUCs of $\triangle \mathrm{PCT}$ (AUC $0.712,95 \% \mathrm{Cl}$ $0.59-0.84, p=0.001$ ), $\triangle \mathrm{CRP}$ (AUC $0.642,95 \% \mathrm{Cl} 0.52-0.77, \mathrm{p}=0.027$ ). (Table 3). The optimal cut-off point of $\triangle \mathrm{PCR}$ was -0.05 for 28 -day mortality, and the sensitivity and specificity for 28-day mortality were $62.9 \%$ and $89.8 \%$ (Table 4 ).

\section{Discussion}

In our study, we evaluated the kinetics of inflammatory variables including CRP and PCT in terms of their prognostic power in predicting mortality in patients with nosocomial BSI. The main finding of the study is that $\triangle \mathrm{PCR}$ is significantly more effective in predicting 28-day mortality than $\triangle \mathrm{CRP}$ and $\triangle \mathrm{PCT}$ alone. There are several studies investigating the predictive value of inflammatory indicators such as CRP and PCT in mortality in critically ill patients $[5,8,26,27]$. According to our knowledge, this is the first article reporting the association between $\triangle \mathrm{PCR}$ and hospital mortality in patients with nosocomial BSI. Our data suggest that combined assessment of $\triangle P C T$ and $\triangle \mathrm{CRP}$ could increase the predictive value of these parameters. For $\triangle P C R$, it was found that the intersection point of -0.05 is predicting the 28 days mortality by ROC curve. The results of this study make contribution to the literature on the prognostic role of $\triangle \mathrm{PCR}$ on mortality in critically ill patients.

Timely diagnosis and treatment are required to reduce bacteremia-related morbidity and mortality [9]. Serum PCT and CRP have good clinical diagnosis and prognostic value for patients with sepsis and septic shock. Kinetic studies of PCT and CRP may increase sensitivity and accuracy when evaluating the prognosis of patients with sepsis and septic shock [28]. They have been used for early detection of infection and directing antibiotic therapy [8]. PCT level was higher in patients with nosocomial BSI and was more useful for predicting nosocomial BSI than CRP or white blood cell count [4]. PCT change faster than CRP in response to bacterial infection, and proper antibiotic therapy is associated with a rapid decrease in PCT levels [25]. A systemic review and meta-analysis study showed that PCT levels were significantly different between surviving and non-surviving sepsis patients [29]. The prognostic value of CRP and PCT kinetics has been studied in several types of infection, with mortality as the main outcome variable. Initial CRP and PCT cannot be considered useful markers in patients with acute and chronic 
conditions [8]. In recent studies, different results have been observed on the relationship of PCT and CRP levels with mortality [30,31]. CRP and PCT kinetics in the first days were associated with use of appropriate (active) empirical therapy [26, 32]. A large multicenter prospective study showed that the decrease in PCT levels by more than $\% 80$ was a predictor of mortality and can be used in managing sepsis [26]. In another prospective study, initial levels of CRP and PCT and their combinations in patients with sepsis, were found to have limited value in predicting 28 days mortality [8]. In our study, we did not find basal (day 1 of BSI) levels of CRP, PCT and PCR significant at 28-day mortality. However, we found the kinetics that reflect the differences between the $5^{\text {th }}$ and $1^{\text {st }}$ days to predict mortality. In particular, PCR kinetics was remarkable in terms of prediction $(\mathrm{OR}=36.8)$. It is thought that PCR kinetics are thought to be superior in predicting mortality due to PCT levels rises and falls earlier than CRP and CRP are affected more by non-infectious diseases than PCT.

Recently, there were reports on the benefit of the PCR in various infectious conditions of adult patients. In a study on the adult pneumonia, log PCR was significantly higher in patients with Legionella pneumonia compared with pneumococcal pneumonia concluding that PCR resulted in excellent discrimination between infections caused by these two pathogens. It was because increase of CRP was more significant than PCT in Legionella pneumonia patients. [20]. Similarly, different increasing patterns of CRP and PCT were found in suspected sepsis group and the proven sepsis group in the present study, which was reflected in the decreased log PCR as well [22]. In addition, Hangai et al. reported that PCR showed best performance in discrimination between tumor fever and infection induced fever in patients with hematological diseases (CRP AUC 0.67, PCT AUC 0.70, and PCR AUC 0.75). These results implicate that PCT and CRP differently respond to various infectious conditions, which makes PCR as a potential tool in differentiation of various infectious diseases [21]. In other study, PCR showed highest AUC compared with CRP and PCT in discrimination of proven sepsis and suspected sepsis in neonates even though there was no statistical difference [22]. In our study, ROC analysis showed that PCT was more useful than $\mathrm{CRP}$ in terms of the AUC. Furthermore, $\triangle \mathrm{PCR}$ was the best test to discriminate between surviving and non-surviving, showing the highest AUC.

Although, there are many scoring systems used to estimate the prognosis of critically ill patients, the $\triangle P C R$ is valuable because it is relatively simple and easy to use in all settings. However, there are several limitations of this study. Firstly, it is a retrospective single center study done on a selected population. There may have been some selection bias because of the study's retrospective design. The patient population might be heterogenous because of various hospitalization settings, including intensive care units. Secondly, PCT and CRP results were reported routinely at our hospital so our clinicians were not blind to the results. This can cause bias and effect the predictive value of PCR. Thirdly, we couldn't investigate the associations of general mortality because cases without BSIs and nosocomial infections other than BSIs were excluded. Nonetheless, PCR was not used in follow up or making up critical decisions for patients.

\section{Conclusions}


This study indicates that higher PCR kinetics was associated with higher mortality rate in ICU patients with nosocomial BSI. We suggest to use $\triangle \mathrm{PCR}$ as an auxiliary test in the follow-up of these patients. But the sensitivity and specificity rate of $\triangle \mathrm{PCR}$ for predicting mortality was not at the ideal height. So, larger multicentral studies are needed to verify this result.

\section{Declarations}

\section{Authors' contributions}

INH designed the study. INH and BD collected and INH analyzed the statistical data. INH drafted the manuscript. INH, BD and TA modified the manuscript and finally approved the version to be published. All authors read and approved the final manuscript.

\section{Acknowledgments}

Not applicable

\section{Funding}

This research did not receive any specific grant from funding agencies in the public, commercial, or notfor-profit sectors.

\section{Availability of data and materials}

The datasets used and/or analyzed during the current study are available from the corresponding author on reasonable request.

\section{Ethics approval and consent to participate}

This study was approved by the Ethics Committee of Bezmialem Vakif University Hospital. Written informed consent has been obtained from all participants. The data used in this study was anonymized before its use.

\section{Consent for publication}

Not applicable

\section{Competing interests}

The authors declare no conflict of interest

\section{Author details}

${ }^{1}$ Department of Infectious Diseases and Clinical Microbiology, Faculty of Medicine, Balıkesir University, Balıkesir, Turkey. 
${ }^{2}$ Department of Infectious Diseases and Clinical Microbiology, Faculty of Medicine, Bezmialem Vakif University, Istanbul, Turkey.

\section{Abbreviations}

BSI: Bloodstream infection; CRP: C-reactive protein; Procalcitonin (PCT); Albumin (ALB); PAR:

Procalcitonin to albumin ratio; CAR: C-reactive protein to albumin ratio; PCR: Procalcitonin to C-reactive protein ratio; ICU: Intensive care unit; SOFA: Sequential organ failure assessment; APACHE-II: Acute Physiology and Chronic Health Evaluation-II; SD: Standard deviation; SEM: Standard Error of Mean; ROC: Receiver operating characteristic; AUC: Area under the curve; OR: Odds ratio; Cl: Confidence interval; TN: True negative; FN: False negative; TP: True positive; FP: False positive; SN: Sensitivity; SP: Specificity; PPV: Positive predictive value; NPV: Negative predictive value

\section{References}

1. Durdu B, Hakyemez IN, Bolukcu S, Okay G, Gultepe B, Aslan T. Mortality markers in nosocomial Klebsiella pneumoniae bloodstream infection. Springerplus. 2016;5(1):1892.

2. Retamar P, Portillo MM, López-Prieto MD, Rodríguez-López F, De Cueto M, García MV, et al. Impact of inadequate empirical therapy on the mortality of patients with bloodstream infections: a propensity score-based analysis. Antimicrobial agents and chemotherapy. 2012;56(1):472-8.

3. Gutiérrez-Gutiérrez B, Morales I, Pérez-Galera S, Fernández-Riejos P, Retamar P, de Cueto M, et al. Predictive value of the kinetics of procalcitonin and C-reactive protein for early clinical stability in patients with bloodstream infections due to Gram-negative bacteria. Diagnostic Microbiology and Infectious Disease. 2019;93(1):63-8.

4. Cha JK, Kwon KH, Byun SJ, Ryoo SR, Lee JH, Chung J-W, et al. Clinical value of procalcitonin for suspected nosocomial bloodstream infection. The Korean journal of internal medicine. 2018;33(1):176.

5. Kim MH, Ahn JY, Song JE, Choi H, Ann HW, Kim JK, et al. The C-reactive protein/albumin ratio as an independent predictor of mortality in patients with severe sepsis or septic shock treated with early goal-directed therapy. PLoS One. 2015;10(7):e0132109.

6. Mir N, Ho D, Toews J, Walsham J. Procalcitonin and New Biomarkers. Clinical Approaches to Hospital Medicine: Springer; 2018. p. 55-76.

7. Candel FJ, Sá MB, Belda S, Bou G, Del Pozo JL, Estrada O, et al. Current aspects in sepsis approach. Turning things around. Revista Española de Quimioterapia. 2018;31(4):298.

8. Ryoo SM, Han KS, Ahn S, Shin TG, Hwang SY, Chung SP, et al. The usefulness of C-reactive protein and procalcitonin to predict prognosis in septic shock patients: A multicenter prospective registrybased observational study. Sci Rep. 2019;9(1):6579.

9. Jeong S, Park Y, Cho Y, Kim H-S. Diagnostic utilities of procalcitonin and C-reactive protein for the prediction of bacteremia determined by blood culture. Clinica Chimica Acta. 2012;413(21-22):1731-6. 
10. Jones AE, Fiechtl JF, Brown MD, Ballew JJ, Kline JA. Procalcitonin test in the diagnosis of bacteremia: a meta-analysis. Ann Emerg Med. 2007;50(1):34-41.

11. Pan YP, Fang YP, Xu YH, Wang ZX, Shen JL. The Diagnostic Value of Procalcitonin Versus Other Biomarkers in Prediction of Bloodstream Infection. Clin Lab. 2017;63(2):277-85.

12. Ljungstrom L, Pernestig AK, Jacobsson G, Andersson R, Usener B, Tilevik D. Diagnostic accuracy of procalcitonin, neutrophil-lymphocyte count ratio, C-reactive protein, and lactate in patients with suspected bacterial sepsis. PLoS One. 2017;12(7):e0181704.

13. de Jong E, van Oers JA, Beishuizen A, Vos P, Vermeijden WJ, Haas LE, et al. Efficacy and safety of procalcitonin guidance in reducing the duration of antibiotic treatment in critically ill patients: a randomised, controlled, open-label trial. The Lancet Infectious Diseases. 2016;16(7):819-27.

14. Byun MK, Chang YS, Kim HJ, Ahn CM. Usefulness of procalcitonin as a predictor for bacteremia and prognosis in severe sepsis. Eur Respiratory Soc; 2016.

15. Harada K, Sekiya N, Konishi T, Nagata A, Yamada Y, Takezaki T, et al. Predictive implications of albumin and C-reactive protein for progression to pneumonia and poor prognosis in Stenotrophomonas maltophilia bacteremia following allogeneic hematopoietic stem cell transplantation. BMC infectious diseases. 2017;17(1):638.

16. Minatoguchi S, Nomura A, Imaizumi T, Sasaki S, Ozeki T, Uchida D, et al. Low serum albumin as a risk factor for infection-related in-hospital death among hemodialysis patients hospitalized on suspicion of infectious disease: a Japanese multicenter retrospective cohort study. Renal Replacement Therapy. 2018;4(1):30.

17. Luo X, Yang X, Li J, Zou G, Lin Y, Qing G, et al. The procalcitonin/albumin ratio as an early diagnostic predictor in discriminating urosepsis from patients with febrile urinary tract infection. Medicine (Baltimore). 2018;97(28):e11078.

18. Oh J, Kim SH, Park KN, Oh SH, Kim YM, Kim HJ, et al. High-sensitivity C-reactive protein/albumin ratio as a predictor of in-hospital mortality in older adults admitted to the emergency department. Clinical and experimental emergency medicine. 2017;4(1):19.

19. Liu Z, Jin K, Guo M, Long J, Liu L, Liu C, et al. Prognostic value of the CRP/Alb ratio, a novel inflammation-based score in pancreatic cancer. Annals of surgical oncology. 2017;24(2):561-8.

20. Bellmann-Weiler R, Ausserwinkler M, Kurz K, Theurl I, Weiss G. Clinical potential of C-reactive protein and procalcitonin serum concentrations to guide differential diagnosis and clinical management of pneumococcal and Legionella pneumonia. Journal of clinical microbiology. 2010;48(5):1915-7.

21. Hangai S, Nannya Y, Kurokawa M. Role of procalcitonin and C-reactive protein for discrimination between tumor fever and infection in patients with hematological diseases. Leukemia \& lymphoma. 2015;56(4):910-4.

22. Hahn WH, Song JH, Kim H, Park S. Is procalcitonin to C-reactive protein ratio useful for the detection of late onset neonatal sepsis? The journal of maternal-fetal \& neonatal medicine : the official journal of the European Association of Perinatal Medicine, the Federation of Asia and Oceania Perinatal Societies, the International Society of Perinatal Obstet. 2018;31(6):822-6. 
23. Sievert DM, Ricks P, Edwards JR, Schneider A, Patel J, Srinivasan A, et al. Antimicrobial-resistant pathogens associated with healthcare-associated infections summary of data reported to the National Healthcare Safety Network at the Centers for Disease Control and Prevention, 2009-2010. Infection Control \& Hospital Epidemiology. 2013;34(1):1-14.

24. Singer M, Deutschman CS, Seymour CW, Shankar-Hari M, Annane D, Bauer M, et al. The third international consensus definitions for sepsis and septic shock (Sepsis-3). Jama. 2016;315(8):80110.

25. Wu Q, Yang $H$, Kang Y. Combined assessment of $\triangle P C T$ and $\triangle C R P$ could increase the ability to differentiate candidemia from bacteremia. Critical Care. 2019;23(1):271.

26. Schuetz P, Birkhahn R, Sherwin R, Jones AE, Singer A, Kline JA, et al. Serial procalcitonin predicts mortality in severe sepsis patients: results from the multicenter procalcitonin monitoring sepsis (MOSES) study. Critical care medicine. 2017;45(5):781.

27. Gradel KO, Thomsen RW, Lundbye-Christensen S, Nielsen H, Schønheyder HC. Baseline C-reactive protein level as a predictor of mortality in bacteraemia patients: a population-based cohort study. Clinical Microbiology and Infection. 2011;17(4):627-32.

28. Cui N, Zhang H, Chen Z, Yu Z. Prognostic significance of PCT and CRP evaluation for adult ICU patients with sepsis and septic shock: retrospective analysis of 59 cases. Journal of International Medical Research. 2019;47(4):1573-9.

29. Arora S, Singh P, Singh PM, Trikha A. Procalcitonin levels in survivors and nonsurvivors of sepsis: systematic review and meta-analysis. Shock. 2015;43(3):212-21.

30. Li Q, Gong X. Clinical significance of the detection of procalcitonin and C-reactive protein in the intensive care unit. Experimental and therapeutic medicine. 2018;15(5):4265-70.

31. Siddiqui I, Jafri L, Abbas Q, Raheem A, Haque AU. Relationship of serum procalcitonin, C-reactive protein, and lactic acid to organ failure and outcome in critically ill pediatric population. Indian journal of critical care medicine: peer-reviewed, official publication of Indian Society of Critical Care Medicine. 2018;22(2):91.

32. Odermatt J, Friedli N, Kutz A, Briel M, Bucher HC, Christ-Crain M, et al. Effects of procalcitonin testing on antibiotic use and clinical outcomes in patients with upper respiratory tract infections. An individual patient data meta-analysis. Clinical Chemistry and Laboratory Medicine (CCLM). 2017;56(1):170-7.

\section{Tables}

Table 1. Characteristics of patients stratified according to 28-day mortality 


\begin{tabular}{|c|c|c|c|c|c|}
\hline \multirow[t]{2}{*}{ Variables } & \multirow{2}{*}{$\begin{array}{l}\text { Survivors } \\
(n=49)\end{array}$} & \multirow{2}{*}{$\begin{array}{l}\text { Deaths } \\
(\mathrm{n}=35)\end{array}$} & \multirow[t]{2}{*}{$p$-Value } & \multicolumn{2}{|c|}{ Logistic regression analysis } \\
\hline & & & & OR $(95 \% \mathrm{CI})$ & $p$ value \\
\hline \multicolumn{6}{|l|}{ Demographic data } \\
\hline Age, years & $64.3 \pm 18.0$ & $62.6 \pm 17.1$ & 0.666 & & \\
\hline Male sex & $23(46.9)$ & $17(48.6)$ & 0.883 & & \\
\hline \multicolumn{6}{|l|}{ Co-morbidities } \\
\hline Diabetes mellitus & $14(28.6)$ & $16(45.7)$ & 0.106 & & \\
\hline Hypertension & $21(42.9)$ & $16(45.7)$ & 0.795 & & \\
\hline Chronic pulmonary disease & $8(16.3)$ & $10(28.6)$ & 0.178 & & \\
\hline Malignancy & $7(14.3)$ & $5(14.3)$ & 1.000 & & \\
\hline Renal disease & $7(14.3)$ & $14(40.0)$ & 0.007 & & \\
\hline Cardiac disease & $12(24.5)$ & $16(45.7)$ & 0.042 & & \\
\hline Neurological disorder & $27(55.1)$ & $14(40.0)$ & 0.172 & & \\
\hline Recent surgical operation & $10(20.4)$ & $13(37.1)$ & 0.090 & & \\
\hline Trauma & $8(16.3)$ & $2(5.7)$ & 0.139 & & \\
\hline Catheter-related bloodstream infection* & $28(57.1)$ & $18(51.4)$ & 0.604 & & \\
\hline Sepsis* & $20(40.8)$ & $12(34.3)$ & 0.543 & & \\
\hline Septic shock* & $4(8.2)$ & $15(42.9)$ & $<0.001$ & & \\
\hline \multicolumn{6}{|l|}{ Microorganisms } \\
\hline Gram-positive bacteria* & $5(10.2)$ & $8(22.9)$ & 0.114 & & \\
\hline Gram-negative bacteria* & $35(71.4)$ & $23(65.7)$ & 0.576 & & \\
\hline Fungi (Candida spp.)* & $9(18.4)$ & $4(11.4)$ & 0.386 & & \\
\hline \multicolumn{6}{|l|}{ Treatment } \\
\hline Appropriate empirical treatment* & $29(59.2)$ & $13(37.1)$ & 0.046 & & \\
\hline \multicolumn{6}{|l|}{ Severity scores } \\
\hline Maximum SOFA* & $7.3 \pm 2.4$ & $10.2 \pm 2.7$ & $<0.001$ & & \\
\hline APACHE-II score* & $16.0 \pm 4.0$ & $21.9 \pm 4.8$ & $<0.001$ & $1.46(1.20-1.78)$ & $<0.001$ \\
\hline \multicolumn{6}{|l|}{ Laboratory parameters } \\
\hline $\mathrm{CRP}, \mathrm{mg} / \mathrm{dL}^{*}$ & $16.7 \pm 8.2$ & $15.6 \pm 7.2$ & 0.513 & & \\
\hline PCT, ng/mL* & $21.3 \pm 30.8$ & $17.9 \pm 29.8$ & 0.615 & & \\
\hline $\mathrm{PCR}^{*}$ & $1.7 \pm 2.9$ & $0.9 \pm 1.3$ & 0.121 & & \\
\hline White blood cell count $\left(\times 10^{3} / \mu \mathrm{L}\right)^{*}$ & $14.7 \pm 7.5$ & $15.9 \pm 10.6$ & 0.550 & & \\
\hline Platelet $\left(\mathrm{x} 10^{3} / \mu \mathrm{L}\right)^{*}$ & $230.5 \pm 112.7$ & $158.9 \pm 107.2$ & 0.004 & & \\
\hline Hemoglobin, $\mathrm{g} / \mathrm{dL}^{*}$ & $9.1 \pm 1.7$ & $9.0 \pm 1.9$ & 0.750 & & \\
\hline Albumin, $\mathrm{g} / \mathrm{dL} *$ & $2.6 \pm 0.4$ & $2.5 \pm 0.4$ & 0.941 & & \\
\hline Alanine transaminase, $\mathrm{IU} / \mathrm{L}^{*}$ & $41.3 \pm 50.1$ & $47.1 \pm 63.3$ & 0.640 & & \\
\hline Total bilirubin, mg/dL* & $1.3 \pm 2.7$ & $2.2 \pm 2.5$ & 0.144 & & \\
\hline Sodium, mmol/L* & $140.0 \pm 4.6$ & $141.5 \pm 6.5$ & 0.222 & & \\
\hline Creatinine, $\mathrm{mg} / \mathrm{dL}^{*}$ & $1.3 \pm 1.5$ & $1.9 \pm 1.5$ & 0.093 & & \\
\hline$\Delta \mathrm{CRP}$ & $-7.3 \pm 8.8$ & $-2.2 \pm 10.0$ & 0.004 & $1.18(1.04-1.34)$ & 0.009 \\
\hline$\triangle \mathrm{PCT}$ & $-18.6 \pm 27.8$ & $-2.7 \pm 38.4$ & $<0.001$ & $0.87(0.79-0.95)$ & 0.001 \\
\hline$\triangle \mathrm{PCR}$ & $-1.3 \pm 2.5$ & $1.4 \pm 6.3$ & 0.025 & $36.78(4.52-299.01)$ & 0.001 \\
\hline
\end{tabular}

Values are presented as numbers (\%) or mean \pm standard deviation

Abbreviations: $\Delta$, Delta deviation $5^{\text {th }}$ day $-1^{\text {st }}$ day; SOFA, Sequential Organ Failure Assessment; APACHE, Acute Physiology and Chronic Health Evaluation; CRP, C-reactive protein; PCT, procalcitonin; PCR, procalcitonin to C-reactive protein ratio; OR, odds ratio; CI, confidence interval; *data of $1^{\text {st }}$ day of BSI

Table 2. Microorganisms isolated from blood culture 


\begin{tabular}{lc}
\hline Microorganisms & Isolates \\
\hline Gram negative bacteria & 58 \\
Klebsiella pneumoniae & 16 \\
Acinetobacter baumannii & 12 \\
Serratia marcescens & 10 \\
Pseudomonas aeruginosa & 7 \\
Stenotrophomonas maltophilia & 5 \\
Enterobacter spp & 3 \\
Escherichia coli & 2 \\
Others (Morganella spp, Ralstonia spp, Achromobacter $\mathrm{spp}$ ) & 3 \\
Gram positive bacteria & 13 \\
Methicillin-resistant coagulase negative staphylococci (MRCNS) & 8 \\
Methicillin-resistant Staphylococcus aureus (MRSA) & 2 \\
Enterococcus faecalis & 2 \\
Corynebacterium striatum & 1 \\
Fungi & 13 \\
Candida parapsilosis & 7 \\
Candida albicans & 5 \\
Candida glabrata & 1 \\
\hline
\end{tabular}

Table 3. ROC analysis for 28-day mortality

\begin{tabular}{lllll}
\hline Variables & Area & SEM $^{\mathrm{a}}$ & $\mathrm{p}^{\mathrm{b}}$ & $95 \%$ CI \\
\hline$\Delta \mathrm{PCR}$ & 0.745 & 0.061 & $<0.001$ & $0.62-0.87$ \\
$\Delta \mathrm{PCT}$ & 0.712 & 0.064 & 0.001 & $0.59-0.84$ \\
$\Delta \mathrm{CRP}$ & 0.642 & 0.063 & 0.027 & $0.52-0.77$ \\
\hline
\end{tabular}

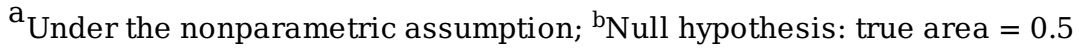

Abbreviations: $\Delta$, Delta deviation $5^{\text {th }}$ day - $1^{\text {st }}$ day; CRP, C-reactive protein; PCT, procalcitonin; PCR, procalcitonin to C-reactive protein ratio; SEM, standard error of mean; CI, confidence interval

Table 4. Comparison of the diagnostic performance of each factor in predicting 28-day mortality

\begin{tabular}{|c|c|c|c|c|c|c|c|c|c|}
\hline Variable & Cut-off point & TN & FN & TP & FP & SN & SP & PPV & NPV \\
\hline$\Delta \mathrm{PCR}$ & -0.05 & 44 & 13 & 22 & 5 & 62.9 & 89.8 & 81.5 & 75.9 \\
\hline$\Delta \mathrm{PCT}$ & -1.45 & 31 & 18 & 22 & 13 & 62.9 & 63.2 & 55.0 & 70.4 \\
\hline PCR ( $5^{\text {th }}$ day) & 0.19 & 33 & 8 & 27 & 16 & 77.1 & 67.3 & 62.8 & 80.5 \\
\hline PCT ( $5^{\text {th }}$ day) & 1.98 & 37 & 8 & 27 & 12 & 77.1 & 75.5 & 69.2 & 82.2 \\
\hline
\end{tabular}

Abbreviations: $\Delta$, Delta deviation $5^{\text {th }}$ day - $1^{\text {st }}$ day; PCT, procalcitonin; PCR, procalcitonin to C-reactive protein ratio; TN, true negative; FN, false negative; TP, true positive; FP, false positive; SN, sensitivity; SP, specificity; PPV, positive predictive value; NPV, negative predictive value

\section{Figures}




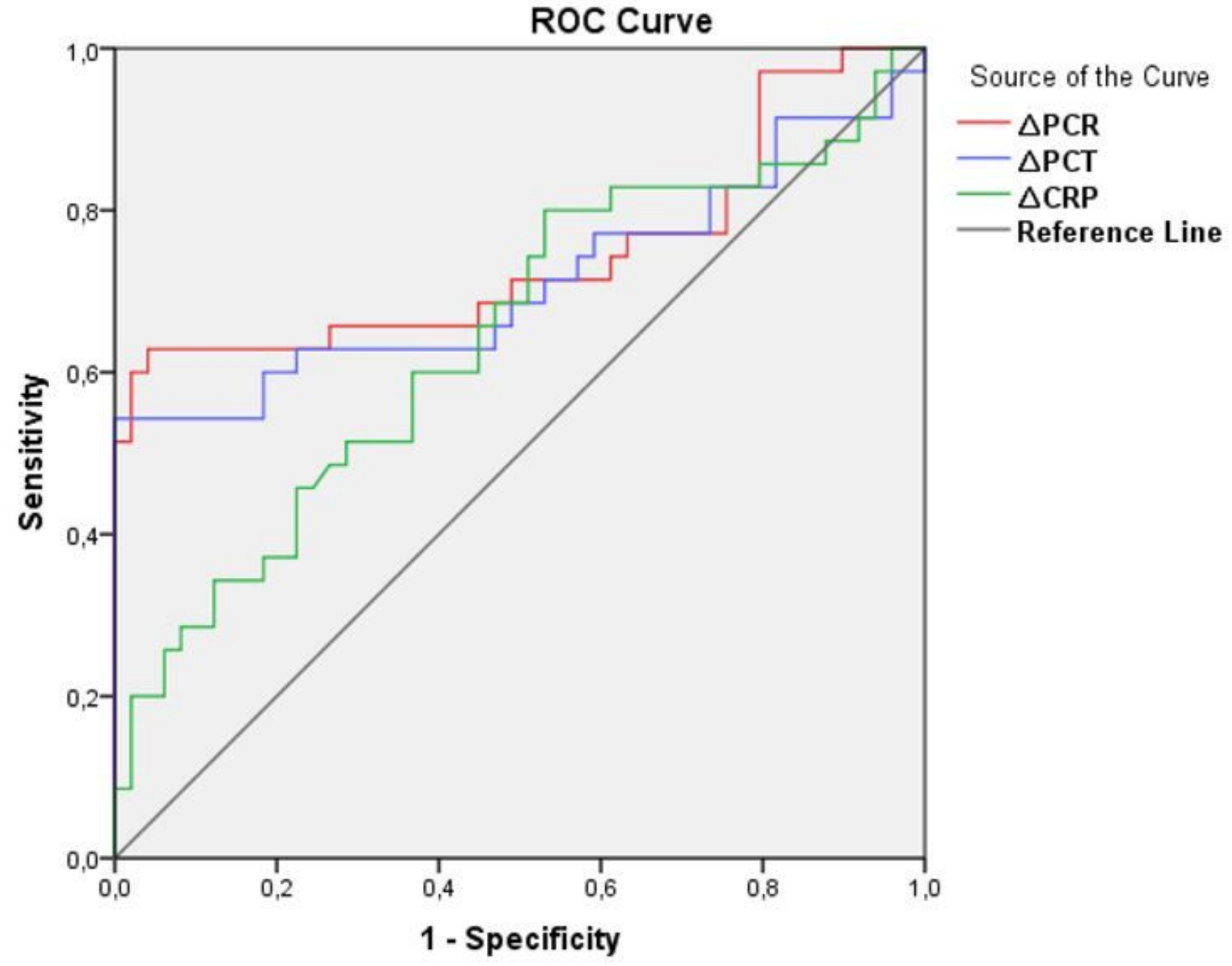

Diagonal segments are produced by ties.

Figure 1

ROC curves of $\triangle \mathrm{PCR}, \triangle \mathrm{PCT}$ and $\triangle \mathrm{CRP}$ as 28-day mortality predictors. 